\title{
Local curriculum development as object construction: A sociomaterial analysis
}

Corresponding author: Eli Tronsmo eli.tronsmo@iped.uio.no

Co-author: Monika Nerland

\begin{abstract}
This paper examines teachers' local curriculum development by analyzing such development as a process of object construction. One team of lower secondary school teachers, mandated to develop a subject curriculum for their school, was followed closely over a year through an ethnographic approach. Data from six team meetings were analyzed to trace how the curriculum was developed through a series of object instantiations that also worked on the construction process. This process required various forms of epistemic engagement, which should be acknowledged in current discussions of teachers' work and their extended professional responsibilities.
\end{abstract}

Keywords: Curriculum development; Object construction; Teacher collaboration; Epistemic responsibilities; Secondary education

\section{Highlights:}

- Teachers develop local curricula by constructing a series of intermediate objects.

- These intermediate objects act back on the planning process in important ways.

- The plan emerges as an unfolding object with multiple connections in time and space.

- Teachers' curriculum work is situated in local and extended knowledge networks.

- Local curriculum development requires extended epistemic responsibilities.

\section{Introduction}

The role of teachers as co-producers of professional knowledge, rather than as practitioners who merely put given knowledge to work in educational practices, is increasingly being recognized. Teaching is situated in a complex landscape of standards and templates, a myriad of research 
contributions, practitioner-developed resources that are shared within and across schools, and expectations from different stakeholders that often generate conflicting concerns (Fransson \& Grannäs, 2013; Jonasson, Mäkitalo, \& Nielsen, 2015). Navigating in this landscape and making relevant use of the resources provided requires analytical skills, as well as the capacity to adapt and construct knowledge and tools to support the school's local needs. Such forms of engagement entail extended responsibilities for developing and safeguarding knowledge for local use, which brings a stronger epistemic dimension to professional work (Author, 2012). Moreover, these extended responsibilities brings collaborative knowledge work to the fore as a way of fostering collective, rather than personal, autonomy in the profession (Hermansen, 2017).

One of the instances where these extended responsibilities are at play is in local curriculum development; as such work is intersected between general standards and local needs and involves a range of epistemic and social concerns. Several researchers have examined how curricular reforms are worked on in schools and local teacher communities and shown, for instance, how such work requires extensive organizational sense-making (Coburn, 2001), how it requires a shared professional language to focus on the same problems (Horn \& Little, 2010), how the route to new teaching practices often involves a reconstruction of existing practices and actor relations (Author, 2014), and how it affords and requires new forms of agency among the teachers (Priestley, Edwards, Priestley \& Miller, 2012; Pyhältö, Pietarinen, \& Soini, 2015). Studies have also highlighted the essential material dimension of curriculum development, in the sense that it involves the construction, adaptation, and redesign of curriculum materials, such as written plans, assessment rubrics, activity templates, and so forth (Voogt, Westbroek; Handelzalts, Walraven, McKenney, Pieters \& DeVries, 2011). As a consequence, increased attention is given to teachers as curriculum designers and to how these processes provide learning opportunities in teachers' work (Voogt, Laferrière, Breuleux, Itow, Hickey \& McKenney, 2015). This research has resulted in a strand of literature that has focused on how teachers design instructional environments, often also related to technology use (Goodyear, 2015; Vestøl \& Lund, 2017). However, we do not have a good understanding of the way teachers actually go about constructing a local curriculum that spans several grade levels or what these epistemic responsibilities entails. To investigate these issues, it is necessary to follow design processes in depth and over time, investigating how they evolve in specific epistemic and material environments. In short, we argue that a threefold 
focus is needed on what is constructed, how it is constructed, and the implications of the temporary constructions for the further design process.

This article contributes to this focus by employing a sociomaterial perspective on local curriculum development by analyzing such development as processes of object construction. More specifically, we draw on Knorr Cecina's notion of "Knowledge objects" as open-ended and unfolding. By regarding the curriculum-in-the-making as an evolving knowledge object, we analyze the development process in a team of lower secondary school teachers in Norway who are mandated to develop a subject curriculum (in our analysis referred to as "the plan") for their school. This analytical approach has been used to reveal design processes and collaborative knowledge construction in other professional areas, such as in architectural design (Comi \& Whyte, 2017; Ewenstein \& Whyte, 2009), construction design (Miettinen \& Paavola, 2016), and in the development of clinical procedures for nurses' work (Author, 2012); however, this approach has not been employed much in studies of the teaching profession. The analysis shows how the teachers construct a series of intermediary objects through which the plan evolves and how these intermediary objects become consequential for the planning process, as well as for the epistemic engagement the process entails. We discuss how the object construction allows teachers to juggle different concerns and to navigate in multiple timescapes and conclude by pointing to possible implications for the teaching profession. Such implications may entail to challenge schools and teacher education programs to prepare teachers for types of design work in complex settings. Before presenting the study and its findings, we commence with a brief review of research on teachers' engagement in curriculum development.

\section{Teachers' engagement in curriculum development: A brief review}

Resent research on teachers' engagements in curriculum development have investigated various aspects of teachers' design processes. One strand of literature has looked at the merits of work in teacher design teams (TDT's). Here, TDT's have been described and investigated in terms of their benefits for school improvement (Handelzalts, 2009; Law \& Nieveen, 2010) and school change (Huizinga, Handelzalts, Nieveen, \& Voogt, 2014), and of enhancing specific topics and subjects (i.e., Pepin, Xu, Trouche, \& Wang, 2017; Voogt et al., 2011). Other reported merits of team engagement in curriculum development are professional learning (Lewis, Perry, \& Hurd, 
2009; Shawer, 2010; Vescio, Ross, \& Adams, 2008; Voogt et al., 2011; Voogt et al., 2015). In this regard, learning is related to teachers' collaborative work on developing resources for practical teaching and experimenting with new instructional strategies for their subjects, as described by Binkhorst, Handelzalts, Poortman, and Van Joolingen (2015). They investigated networked TDT's in the Netherlands and found that TDT's promote teacher professional development, especially in cases where a team coach contributes to defining a shared goal. Another strand of literature has looked at what it entails to engage in these designs, showing how teachers work with and on different kinds of representation e.g. abstract ideas and concrete materials. Some researchers have conceptualized this as prototyping (McKenney, Nieveen \& Van den Akker, 2006; van den Akker \& Kuiper, 2008; Plomp 2013) which refers to the systematic process of revision of design products in iterative cycles during the design process. In a study of 12 teacher design teams in the Netherlands during their effort to redesign their curriculum, Handelzalts (2009) found that the most conducive activities in teacher design teams were those that 'forced' the teams to define their rationale and their goals while the teams collaborated on concrete materials. Setting abstract ideas on paper made them tangible and accessible for discussion and assisted teachers in creating concrete images of possible future practice. Also, in an ethnographic study of curriculum making in Scotland, Priestly and Drew (2017) reported that teachers' space and repertoires for maneuvering were shaped by material and social configurations of the context. Development conducted by the teachers acted as a translator of externally and internally initiated ideas in ways that implied reconstruction of existing practice. Baker-Doyle and Gustavsen (2016) showed in their study in the U.S. context how cultural tools are influenced by and influence teacher agency and point to the complexity and different concerns that are embedded in what they call the "small moments" of micro-level interactions during collaborative curriculum design.

In sum, what all these studies illustrate is that teachers gain increased responsibility for constructing, adapting, and redesigning instructional resources. As explicitly discussed by McKenney, Kali, Markusaite, \& Voogt (2015) these studies have provided valuable insight into the complexity of collaborative curriculum development and expanded our understanding of how teachers as curriculum designers work at many levels in parallel while creating and interacting with external representations. However, most of these studies have conceptualized design as the 
detailed process of imagining and constructing specific artefacts for instructional use (McKenney et al., 2015). Although teachers' extended responsibilities are illuminated in the literature, we need more insights into the epistemic dimensions of such responsibilities. That is, how teachers handle various knowledge forms and concerns, how they explore new and established practices across time and space, and how they justify decisions made in the construction process.

In what follows, we examined the epistemic facets of teachers' work in a case study of how a team of lower secondary school teachers in Norway construct a subject curriculum for their school. This work takes place at what van den Akker et al. (2006) describes as 'the meso level', between classroom practice and guidelines from national level and the school itself. Norway is an interesting context in which to examine such processes, as teachers are given responsibility for local curriculum development. There are national regulations, but these are not very fine grained and more specific plans for the school needs to be developed locally (Hatch, 2013). Therefore, tensions between external regulation and professional maneuver are present, however, to a lesser extent than in England or the US, for example (Czerniawski, 2011). The study analyzes the process of constructing a subject curriculum that should be applied across classes and grades in the school, rather than on the design of specific learning materials. Such work actualizes a broader set of regulations across different subjects and makes it possible to examine curriculum development at the intersection of national regulations and local concerns.

\section{Conceptualizing curriculum development as object construction}

In order to investigate curriculum development as a construction process, we need to attend to the processes as they unfold, and to the various resources teachers relate to in this work. A theoretical perspective suitable for understanding such emergent relations is the sociomaterial perspective on professional practice (Fenwick, Edwards, \& Sawchuk, 2011). In such an approach, a central assumption is that practices are relationally constituted by humans and the material world that capture, give shape to, and embody the knowledge of a given domain or across domains. A second assumption is that practices, i.e., collective ways of doing or acting, are constituted by forms of materiality and resources (e.g. policy documents, subject-specific and pedagogical discourses, standards and technologies) that are encountered and acted upon. In curriculum development processes, certain materialized representations of social conventions, 
educational standards, and priorities or curriculum understandings may have a greater impact than others. At other times, established practices may be challenged by new ideas or new cultural resources. What emerge are situations that call for considering and balancing interests and concerns. The third assumption takes into consideration that relations, meanings, actions, and knowledge are always in a state of emergence. For professional practice, this state implies that knowledge and resources are translated as they are enacted in practice, and this translation involves transformative and stabilizing forces (Author, 2012). Analytically, this approach draws attention to the complex web of demands, people, activities, and standards, of which the work of today's teachers is embedded, found in and structured by schedules, calendars, plans, and teaching syllabuses teachers design for work in the future but also in view of previous experiences and practices. Regardless of how fixed planning work may seem, it is always dynamic, emergent, and constructed in ways that involve translation processes.

Sociomaterial theories comprise several potential approaches to study object construction ${ }^{1}$. For this article we draw on one concept within the sociomaterial perspective that allows us to explore the epistemic and relational dimensions of the construction process; the concept of "knowledge objects" (Knorr Cetina, 1999, 2001; Author 2012). Knorr Cetina emphasizes that objects of knowledge are both things and processes. Such objects are bounded but unfolding and infinitely expanding; they are "both ready at hand and subject to further development and investigation" (Knorr Cetina, 2001, p. 187). To exemplify the notion of knowledge objects Knorr Cetina refers to computer programs; they are continually changing but simultaneously ready-to-be-used. This duality has especially two important analytical implications. First, a defining characteristic of knowledge objects is their incompleteness. Their properties emerge and progress only when they are explored and worked on. Knowledge objects "are always in the process of being materially defined" and "continually acquire new properties and change the ones they have" (Knorr Cetina, 2001, p. 181). In this sense, knowledge objects as wholes are never fully available and emerge only when partial aspects are worked on. Second, as knowledge objects frequently exist

\footnotetext{
${ }^{1}$ These include, for instance, Cultural Historical Activity Theory (CHAT), Complexity Theory and Actor Network Theory. CHAT has been used in several studies of teachers' work and highlights the role of objects and motives in activity systems. The present study is more limited in the empirical scope and takes particular interest in the epistemic dimension of teachers' construction process. We find that the concepts of knowledge objects and intermediary objects are productive to investigate these issues. For a further discussion on sociomaterial approaches in educational research, see Fenwick et al. 2011.
} 
simultaneously in a variety of forms, they carry a temporal duality: one pointing forward in time to the thus far incomplete or not yet fully accomplished state and one expressed through representations of a past or present state. A knowledge object as an analytical concept allows us to analyze how the plan is constructed and what is being constructed.

The relations of these two versions of an object have been characterized as "instantiations" of the knowledge object (Vinck, 2012) connecting the abstract (ideational) and the concrete aspects. In order to open up the construction process, we draw on the concept of "intermediary objects" (Vinck, 2012; Vinck, Jeantet, \& Laureillard, 1996) to understand the various functions the object may have in the construction process. First, the intermediary object functions as a mediator in the sense that its materiality provides a focal point where ambiguities can be sorted out, surprises may appear, and meaning translated. Second, in following intermediary objects, we can describe the emergence of a solution because the materiality of the object builds and restricts the dynamics at work by making it possible to coordinate input from different actors; to stabilize some aspects, and to develop others. The concept is suitable for comprehending the many, temporary versions of the curriculum under construction. Third, intermediary objects define and delimit a space for action (Vinck, 2012), for example, by defining what should happen in public or private spaces, who should have control over usage of the objects, who might account for them, etc.

By using these concepts of knowledge objects and intermediary objects and their various functions as sensitizing means, this study aims at opening up the process of curriculum development as object construction by examining how the plan as a knowledge object is constructed through a series of intermediary objects. As formulated by Vinck, these intermediary objects act back on the construction process by framing the actions, structuring the time frames, and mediating a common ground for the work. In the next sections we use these perspectives to explore the following three questions that guide our analysis:

\section{What characterizes curriculum development as a process of object construction?}

2. What role do the intermediary objects take in this process?

3. What kind of epistemic responsibilities are required by the teachers in this process? 


\section{Empirical setting and method}

One school was selected as the empirical site for the study. We contacted several lower secondary schools that were development-oriented, and from among the interested schools, we selected the school at which local curriculum development was a priority area. The school's curriculum development initiative originated from a status analysis conducted by the school two years earlier which had revealed a desire among the staff to broaden their general curriculum understanding and to get more time to immerse themselves in their subjects across levels, regarding the overall purposes of the disciplines and the inherent principles of the subjects. The teachers had also requested more time to collaborate across subjects in order to deepen certain topics from multiple angles. Consequently, school management organized all teachers in subject specific teams and gave them the mandate to meet regularly in subject groups: six times per year, two hours per meeting, in addition to planning days, in order to develop a school-based curriculum within their respective subjects. Neither management nor teachers had previous experience with curriculum development. In the interviews it emerged that the teachers had a widely shared understanding of the job. A long-term expectation was to develop a complete yet flexible product that provided a common standard, which, in turn, was expected to enable them to allocate more time to develop diverse teaching methods and learning promoting assessment practices. The subject curriculum was intended to have a validity frame of three years, but the methodology and syllabus were to be revised annually. In the mandate given to the teachers, laborious work that, among others, required an overview of the subject content, methodology, learning theories, and pedagogical skills, was expected. A template for curriculum components to be included in the plan was developed in collaboration by management and teachers. Table 1 shows how this template was presented as a starting point for the teachers' work. The curriculum components were: competence aims in the national curriculum; a local plan for social and cultural activities connected to the national core curriculum (i.e. addressing attitudes and knowledge); skills; subject content; teaching methods, excursions, and teaching resources; and assessment (how and when). The design of the template (Table 1) was a result of policies, national requirements, research, and school priorities and thus, a carrier of work dispersed through space and temporalities. 


\section{Table 1}

General template for the development of the subject curriculum.

\begin{tabular}{|c|c|c|c|c|c|}
\hline \multicolumn{6}{|c|}{ Subject curriculum XXX. Grade Y } \\
\hline $\begin{array}{l}\text { Competence aims } \\
\text { (National } \\
\text { Curriculum K06) }\end{array}$ & $\begin{array}{l}\text { Social and } \\
\text { Cultural plan }\end{array}$ & Skills & Teaching & $\begin{array}{l}\text { Teaching } \\
\text { materials/ } \\
\text { excursions }\end{array}$ & Asessment \\
\hline $\begin{array}{l}\text { Relevant Subject } \\
\text { specific } \\
\text { Competence aims } \\
\text { from the national } \\
\text { curriculum }\end{array}$ & $\begin{array}{l}\text { The Acts governing } \\
\text { Education }+ \\
\text { National Core } \\
\text { Curriculum }\end{array}$ & $\begin{array}{l}\text { All skills, including } \\
\text { Basic Skills as } \\
\text { articulated in the } \\
\text { National Curricula } \\
\text { Competence } \\
\text { recognition of verbs } \\
\text { Including } \\
\text { preparation of } \\
\text { assessment tests }\end{array}$ & $\begin{array}{l}\text { Descriptions of the } \\
\text { teaching cf. } \\
\text { previous columns } \\
\text { (e.g., teaching } \\
\text { students the use of } \\
\text { map and compass } \\
\text { and measure) }\end{array}$ & $\begin{array}{l}\text { Examples of } \\
\text { teaching materials, } \\
\text { methods, field trips }\end{array}$ & $\begin{array}{l}\text { When and how } \\
\text { assessment will take } \\
\text { place (also to be } \\
\text { enshrined in the } \\
\text { annual plan); } \\
\text { Interdisciplinarity } \\
\text { coordinated in } \\
\text { August }\end{array}$ \\
\hline
\end{tabular}

In each group, one of the teachers was responsible for running the process, including referring and having regular meetings with the principal and the other subject group coordinators. In the group we followed, the meetings had a structured agenda with agenda items introduced by the coordinator. Although some themes recurred from meeting to meeting, new topics were introduced at each meeting although the topics the teachers had been working on had not necessarily been finalized. It was an implicit requirement that certain tasks had to be completed in-between meetings. The principal explained in an interview that the subject curriculum they developed was "binding" in the sense that it would be enshrined in the school's strategy documents and act as documentation in relation to the supervisory authorities. She also explained, however, that "this work will never be quite completed," because, as she added, the teachers" curriculum development was "the best continuing professional development obtainable." This implied that the plan had different purposes, that is, supporting professional development and outward communication to parents and stakeholders, but also for internal teaching practice among teachers and future staff.

In order to study curriculum development as emerging practice in a sociomaterial environment, we took an ethnographic approach to collecting data. We followed six meetings of the subject- 
specific group of the Social Sciences (History, Geography, and Civics) throughout the school year (2015-2016), consisting of six teachers across grade levels (8-10) while they collaboratively developed a Social Sciences curriculum for their school. Three teachers were experienced with postgraduate training in supervision, one was novice, and one had a few years of experience. By using the strategy of "following the object" (Bruni, 2005; CzarniawskaJoerges, 2007), we were particularly concerned about capturing the various versions of the plan in order to ensure sensibility in the material and interactional details as the plan proceeded. The data corpus consisted of observation data, interview data, documents, and resources shared in the teachers' online working space. Observations and interviews were recorded with a video camera and supplemented with handwritten field notes, typed up after each visit and stored in a Fieldwork Activity Log. The interviews were used to elaborate on the observations and the reasoning for the teachers' actions, while additional data were gleaned from other meetings (e.g., grade-level meetings and planning days), and school documents. Video observations and interviews were transcribed verbatim. The focus of the transcriptions was verbal communication, but nonverbal actions relevant to the interaction (Jordan \& Henderson 1995) were included (e.g. as when participants took notes, typed, moved in the room, or used artifacts) ${ }^{2}$. The transcriptions were linked to material representations of the team's work, such as pictures of artifacts in use and draft versions of the plan. Intermediate versions of the plan were downloaded and analyzed to show partial versions of the process. When the observations started, the Social Sciences group had worked with disciplinary content and assessment components in the previous academic year; however, the many empty spaces in the columns and rows indicated that much remained to be done.

\section{Analytical strategy}

For this article, we focused specifically on the teachers' collaborative work during the six meetings. Given our interest in the types of object construction involved in local curriculum

\footnotetext{
2 Transcription conventions

Underline $=$ The speaker is emphasizing or stressing the speech

$(($ italic text $))=$ Annotation of non-verbal activity

$\ldots=$ A brief pause

"italic text"= The speaker reads
} 
development, the process of constructing, exploring, and stabilizing the object and its materialization constitutes the analytic focus of the present study. We followed the object in the making rather than the teachers' intentions (Vinck, 2012; see also Ewenstein \& Whyte, 2009). The analysis was conducted in three steps. First, through repeated readings of the transcripts, field notes, and viewing of the video materials, we approached the ethnographic work with a number of analytical categories (e.g., questions they worked with in the curriculum design, knowledge resources in use, emerging tensions, and actors referred to) formulated through our theoretical and methodological interests. However, we refined these categories during the course of inductively generated readings of the material. Second, following McGivern and Dopson's (2010) strategy, we punctuated key events marking "phases" in order to capture the overarching knowledge object. We looked for intermediary objects and episodes in which the social and material interactions were temporarily summarized or closed by reviewing field notes and transcripts. For instance, after a longer discussion about knowledge content and criteria for learning outcomes, the process could come to a close by way of a conclusion, but this instantiation was likely to be reopened at a later stage. Third, once we had determined these episodes to warrant further analysis, we conducted an in-depth analysis of how the object progressed in and beyond these episodes. To validate interpretations, these were presented to coresearchers in joint data sessions and three researchers systematically compered their interpretations throughout the process.

By analyzing data from all six meetings, we gained insight into the micro-processes of the curriculum development. Although the identified processes were present in all meetings, we selected three empirical episodes to illustrate the processes in which the intermediary object was opened up for further exploration or was stabilized. The ensuing presentations and analysis draw partly on the researchers' constructs of the narratives and partly on extracts of video observations. We do not present these episodes in a linear timeline, but focus on how different versions, options, or solutions were arrived at, and the social and material interactions mobilized in this work. The three events illustrate the different character of these processes. 


\section{Findings: Curriculum work as object construction}

Thorough reviews of the entire data set showed how the teachers needed to explore partial aspects and relations inherent in the knowledge object. In these situations, the teachers created intermediary objects in order to work specifically with areas such as questions of assessment or relations to national guidelines.

We identified three compound problems embedded in the overall knowledge object that the teachers needed to resolve, as well as the epistemic engagement this required. The first episode is from the third meeting when one of the teachers modeled an instructional session on personal finances. The second episode is from the fifth meeting when the group discussed assessment issues, a recurrent topic during the meetings. The third episode from the final meeting illustrates how the various curriculum components were seen in context and alignment sought.

\section{Instantiating curriculum principles through modeling instructional practice: Episode 1}

Minutes before the meeting starts, six teachers appear from various areas of the school, each carrying a laptop. It is 30 minutes since the last pupils left the school, and now the colleagues meet in a Grade 10 classroom and push six student desks together for a meeting table. Oliver, the group leader, immediately writes the (previously distributed) meeting agenda on the whiteboard. The tone is informal and cheerful. Oliver opens their shared online space where the curriculum in progress is located and projects it on the screen, and the meeting starts on time.

Ninety minutes into the meeting, they stop at the leftmost column (see Table 1) in the Grade 10 plan, at a competence aim from the national curriculum represented by the following key words: "The relationship between national and global finances." On this topic, the other columns in the plan are still blank (i.e., the horizontal line). Stephen, one of the 10th-grade teachers, has initiated and prepared to elaborate on this issue with a "modeling" session. Standing behind the podium, he closes the projected window with the Social Sciences plan and opens a PowerPoint slide with the heading "The relationship between micro- and macroeconomics."

Microeconomics is addressed in the mathematics subject curriculum, he says, and opens the 
current version of the mathematics plan which is available in the shared online space and points to the overlap between the two subjects. Again, he opens the Social Sciences plan, and asks, Can we leave this to the mathematics teachers alone? He continues: On this topic, we ought to take our share of responsibility, but then the question is how we can do it in ways that make sense for the students. He adds that he recently attended a breakfast seminar where a professor in social economics shared concerns about youth's lack of understanding of macroeconomics. The group looks at the plan projected on the screen. Next, like an actor in a scene, he simulates a teaching session, using several resources (pictures, narratives, e.g., a Donald Duck story illustrating the phenomenon of inflation, and a diagram from Keynesian economics). The others listen attentively and take notes. After completing this teaching demonstration, the others ask questions and provide suggestions. Stephen's next slides point to research on how macroeconomics affects family finances, followed by statistics on youth's lack of understanding of economics, data from the Red Cross about staggering high consumer loans among adolescents, and research on correlations between mental health and the absence of financial life skills. After ten minutes, he has shared suggestions of didactics and arguments about the relevance of this topic for the Social Sciences subject curriculum. This initiates a discussion about the purposes of the subject. In the following minutes, competence aims and assessment move to the background and the interaction about the teachers' mandate to educate students to become critical citizens fills the room. The teachers agree that the issue needs to be further developed at a later meeting in collaboration with the Mathematics teachers, and after 20 minutes in total, they end the session by materializing a few lines in the empty columns of the plan about methodology, resources, assessment, and interdisciplinary collaboration. This materialization (temporarily) closes the issue.

(Based on observations from meeting 3)

The entry point of this episode was a representation of a curriculum principle from the national curriculum materialized in the plan as a potential link between national and global finances. This "frozen" instantiation projected on the screen served as an intermediary object. However, it turned out that the intermediary object could not easily be inserted in the plan but bred a raft of questions and concerns that needed to be negotiated before the object could be stabilized. Thus, 
in this episode, the intermediary object acted as mediator for manipulating this part of the overarching knowledge object (the local curriculum) by way of an explorative "modeling detour." Thomas, one of the teachers in the group, explained in a group interview, "The thing about modeling is that it gives us insight into the ideas behind different teaching concepts." The modeling served as a tool for translating national curriculum principles. Thus, the functions of the intermediary object came into play in several ways.

First, Stephen produced sketch proposals in the form of slides to externalize his ideas. By offering the group something to hold on to, he mobilized several resources (e.g., pictures, research diagrams, and didactic resources) that created an interpretative framework around the intermediary object. Looking at the slides with his colleagues served as a social and material mediating activity that expanded their interactional repertoire. For example, the Donald Duck story about inflation was related to the development of instructional activities. In engaging with Stephen's externalized ideas, the teachers generated new suggestions, many of which the group had not previously discussed. The discussions brought creative dimensions to work with new and unpredictable outcomes. In asking whether the issue of microeconomics should be left to the Mathematics subject, Stephen's question generated concern for the teachers' responsibilities that led the teachers to investigate specific issues. When this happened, the object was opened up, bringing out explorative discussions about various alternatives of what to include in the different columns in the plan. New questions needed to be clarified before the teachers could move on. For example, in linking the issue of personal finances to the societal mandate of their subject, they simultaneously justified why this issue belonged in the teachers' area of responsibility. Such reasoning efforts brought up the need to align the local curriculum work to the principal aims of the national core curriculum.

The excerpt also shows that the curriculum principle on the screen was translated into a specific example, not only of how this previously had been done in Stephen's class but also how this might be done. Thus, the modeling mediated a synchronization of previous experience and engagement in upcoming teaching and future possibilities. This created a space for switching from the past into an imagined scenario pointing to the future where the group altered between articulating "what if" possibilities and materializing their discussions in the form of on-screen 
text and graphics. The modeling created a complex interplay between temporalities where the teachers combined representations of disparate times and spaces. Rather than solely following the compressed and linear structure of the curriculum template, the teachers' explorative interactions with the intermediary object shaped the temporal and spatial relations. Linked to diverse networks within and beyond the local school, such as classroom practice, other subject meetings, and external seminars, the progression of the local curriculum was thus influenced by practices in other settings and times.

Third, the construction of the plan developed in response to a broader frame of references. When the teachers took notes, asked questions, proposed changes, and solved problems, they brought in nuances from, for instance, work experiences or from research-based knowledge. These nuances were important to the way the construction of the plan moved forward and in determining a direction. For example, by linking the general learning objective to research on high consumer loans among youths, the intermediary object the teachers started with was (re)shaped in relation to the purposes of schooling (and to their societal mandate). This reshaping, in turn, triggered elaborations of relevant teaching methods as illustrated by Stephen's slides and suggestions for educational activities. In addition, in delineating to the Mathematic subject, the relation to the social mission of the Social Sciences subject was reinforced, which, in turn, required specification of interdisciplinary work. The decision to share a new intermediate version of the object with the Mathematics teachers gave the object a preliminary closing that functioned as a temporary stabilized ground from which the construction process collaboratively could move forward.

In summary, this empirical episode illustrates how the use of general principles was not straightforward but required a complex comprehensive effort. We observed forms of translation processes around intermediary objects that took the functions of re-contextualization. This required epistemic engagement from the teachers and responsibility for exploring and stabilizing implications for practice. 


\section{Connecting the plan to general principles: Episode 2}

Another aspect of the object construction was the alternation between specific tasks and general principles. In the second episode, we see how the construction process moved forward by negotiations over core issues, as in this excerpt about assessments.

It is April and seven weeks since their previous meeting. Two minutes before the meeting starts, Oliver writes the agenda items on the whiteboard, hereunder assessment forms. Today, "assessment forms" implies reviewing, specifying, and selecting adequate assessments to be materialized in the plan. The following interaction takes place 20 minutes after the meeting starts. The group's attention is directed to the screen at the column for assessment, after having thoroughly reviewed and justified the different forms of assessment currently in use in the subject at all three grade levels. During the interaction, Oliver listed all the assessment forms uttered by the actors in a side document from which he now reads:

\section{Table 2}

Data extract

Oliver $1 \quad$ Okay. Let me read all the assessment forms we use: "Structured subject 2 conversation, written conceptual test, Structured mind-maps and flip charts, 3 Map and basic arithmetic, Written test, Key-word test, Poster making, Oral 4 presentation, Photo story, Five Paragraph Essay, Panel discussion, Map test, 5 Subject conversation, Presentation + subject conversation, Online multiple 6 choice test, and Subject conversation." That's all the assessment forms we 7 use in the Social Sciences subject in the course of three years.

Rob 8 I think we should be a bit self-critical when it comes to variety. Because here 9 it sounds like we have many different forms, but a number of them are quite 10 similar. I'm not creative enough to.... but there must be.... I mean, I'm 11 chasing the math teachers a bit because I think they are too traditional in their 12 assessment practice. But maybe we are just as traditional? Perhaps it's so that 13 I've had such good experience with subject conversations and then it's easy 14 to get it done, and a little too easy to do it the next time, too?

Anne 15 I think there's a limit to how many forms of assessment we should have. And 
16 I know that my students like, at least that's what they clearly report; that they 17 recognize the assessment form. Because it gives them a sense of security.

18 When they are familiar with the form, they can focus more on content. So I 19 don't believe it should be a goal in itself to have forty different forms of 20 assessment within three years. But it might be a goal to have, let's say four,

21 then. So that they know they'll have four or five different forms in the course 22 of a year and that these are slightly different types. But it's not a goal to have 23 as many different forms of assessment as possible because the students get 24 distracted by it.

Oliver 25 I would add one thing to that. For variety is nice, but another point is that we 26 have to train them in the various assessment forms. We must teach them to 27 write paragraphs when writing the Five Paragraph Essay. We have to teach 28 them techniques for good oral presentation when that's what they are to do.

From video observations, meeting 5

In this excerpt, the entry point was the different assessment forms rattled off by Oliver. This listing acts as an intermediary object in the sense that it serves as an instantiation of principles bridging local and national assessment forms and practices. During the interaction with this list, different concerns, resources, and views on the topic were mobilized, and the teachers tried to navigate between them.

First, the teachers' work on the intermediary object led them to discuss various resources currently in use. The call to expand assessment practices and request for a creative stance promoted by Rob (lines 8-12) relates to a policy initiative on 'Assessment for Learning' (AfL) which had been a priority area for the school in recent years. This had provided the teachers with diverse assessment-related resources to support student learning, developed in different knowledge settings beyond the local community. Such initiatives come with specific motives, policy prejudices, and assumptions about learning that require local adaptation and may be altered in various directions. The various resources linked to the intermediary object mediated a room where further possible avenues were followed or excluded. For example, while Rob argued 
to broaden their assessment practice in terms of variation, Ann, in contrast, questioned the underlying assumption about great variety in assessment forms as essential to improve learning (line 15). In this situation, the intermediary object mediated a space for exploring whether variation is inhibiting or promoting student learning and helped the actors to more specifically articulate their understanding of assessment for learning. Progression toward a shared understanding made their ideas more explicit and thus debatable. This put their current understanding of assessment for learning at stake.

Second, this episode illustrates how the intermediary object incorporated adjustments made by the teachers but also carried tensions about assessment in this setting and beyond. Teachers' negotiations about assessment and student learning rested on previously established networks, practices, and relations, such as the AfL network. When the teachers drew up various alternatives and created concrete images of future assessment practice, they made an explorative detour outside the plan, moving from the specific and concrete to general principles, as when they discussed the more general question about when the number of assessments becomes a distraction for the assessment of subject content. The stabilizing of the object in this episode occurred through the way local and universal specifics were connected. "Universal," here, did not imply a rupture with the existing practice as represented but transforming through it. This example illustrates how the intermediate object stabilized some aspects and developed others, and thus contributed to the unfolding of the subject curriculum as the overarching knowledge object.

Third, the group started in a concrete problem of deciding on numbers and forms of assessment, but when pursued, the problem was elaborated and abstracted, as when the concern for where to draw boundaries between form and content in relation to assessment (lines 18-20) was discussed. Yet another concern brought to the table related to students' right to acquire instruction on the different assessment forms, as in Oliver's utterance (lines 25-27). At this stage, the unfolding knowledge object was conveyed not only as a plan for upcoming teaching and assessment but also as a formalized "contract" and clarification of expectations with students and other stakeholders. An aspect of this relates to how teachers are held accountable through written documentation of their professional practice and triggered the concern for specifying and 
defining sequences of the instruction, amplifying more codified strategies in their practices. After a discussion about how to train students in assessment forms, the process came to an end by way of a conclusion where Oliver's call for procedural aspects superseded the previous principle of variation.

In summary, this episode showed how the larger knowledge object kept unfolding through the teachers' exploration of intermediary objects. By critically considering local assessment forms against established standards, the teachers validated aspects of the plan.

\section{Aligning the parts into a whole: Episode 3}

Another aspect of the object construction was to establish consistency between different parts of the plan. In this episode, we see how the teachers' work moved forward by ensuring the connection between the various components, i.e., between the vertical and horizontal axes, between various timelines, and between what was written in the plan and what was being done. Here is an example of how they work with alignment across the curriculum elements.

It is June, and the end of the school year is approaching. As usual, Oliver has distributed the meeting agenda a few days in advance, and one of the items on the agenda is "Reviewing the entire plan." Previous meetings dealt with section by section, but now the teachers work from the whole by trying to get an overview along and across the columns. What remains before the subject curriculum is operative for the school year to come? New temporal frames have entered the work which triggers other questions: What should be prioritized? What sections are completed, and how are they in sync? One of the areas the teachers had agreed to include in the plan, in addition to content knowledge and assessment, was to ensure that basic skills across subjects were highlighted. The group takes a position on status. Are there skills that have taken precedence over others, Oliver asks, and correspondingly, are there areas not adequately addressed?

The atmosphere in the room is focused. Jessica, now behind the podium, controls the keyboard and adds to the plan. In the following extract from the meeting, the group has stopped at a section halfway through the Grade 8 plan concerning the French and American revolutions. 


\section{Table 3}

Data extract

Oliver 1 ((Looking at the midpart of the $8^{\text {th }}$-grade plan $\left.)\right)$ : I can't see that numeracy as basic

$2 \quad$ skill is covered, up to here?

Thomas 3 Yes, we took care of it during the American and French revolutions: To calculate

4 population in terms of first, second, and third positions. And percentage. It can be put

5 in there.

Jessica $6 \quad$ ((Typing into the plan, while spelling)): "To calculate population with population size and percentage"

Thomas 7 Yes.

Oliver $\quad 8$ Please scroll up again. There has to be something about arithmetic and scale. Yes. It's

9 there. "Arithmetic and scale." Forget it. It's taken care of.

Thomas 10 We have also been teaching a bit about learning strategies. And I believe the

11 American and French Revolution was the first time we started to work with the

12 reading strategy "BISON." We also used "Structured Mind Map," but that's perhaps

13 not typed in either?

Oliver $14 \quad$ It's in there now. Furthest to the right. But have they learned to use it?

Thomas 15 That's part of the process here...

Oliver $\quad 16$ Then it must appear in the plan!

Jessica $17 \quad$ ((Writes, while spelling out loud $))$ : "Teaching how to make Structured Mind maps." 18

Thomas 19 I think it would be a good idea to do this a bit the way we did it. What we did was a 20 bit Flipped classroom-like. Rob filmed himself while making a Structured Mind map 21 and shared it with the students. Then, while teaching about the American Revolution, 22 they got a complete Mind Map from us that could be easily applied. Next, when we 23 came to the French Revolution, they got a semi-finished Structured Mind map to be 24 completed by them. And now, when we come to the Industrial Revolution, they will 25 have to create them from scratch. So, learning how to use them is a gradual process. 26

Mirjam 27 ((Writes $))$ Now it's in the plan

\section{From video observations meeting 6}


In this episode, the teachers carefully scrolled up and down the different columns of the Grade 8 plan to detect inconsistencies in relation to the overall intentions and requirements. In this work, the intermediary object was first constructed as a relation between the subject content and basic skills to investigate, and this relation was mediated by the current version of the plan on the screen. The teachers' effort to continuously stabilize various relations while at the same time exploring them, structured the work in several ways.

First, in the opening of the excerpt above, Oliver, the group leader asked whether numeracy as a basic skill was included in the topic of the revolutions in the Grade 8 plan. This question mediated the investigation of whether the plan in its present form was in accordance with requirements about having the five basic skills integrated in all subjects. Thomas replied that the numeracy skill was taken care of, and they continued to scroll up and down in order to detect potential inconsistencies or omissions. Through temporary "freezing," the relationship between a small section of the plan and another construct (here, numeracy as a basic skill), they created an intermediary object as a shared ground for safeguarding consistency. When this happened, the intermediary object defined boundaries of the further materialization process, as when Thomas pointed to the lines where the plan should be refined (line 5), and Jessica added some words to the plan (line 6). This closed the issue and moved their work a step forward by stabilizing the relation between the subject content and reading as a basic skill (line 12). However, the framework for basic skills was a construct that had to be specified and materially resolved. When these various constructs were translated into written forms, they were turned into new instantiations that shaped the way the object took form.

Second, reviewing and cross-checking the entire plan also implied explorations of the discrepancies between what was actually written in the plan and what was done in practice. For instance, during the interaction, Thomas orally elaborated what they had previously done by referring to the various learning strategies (lines 12-13). Statements like "we did it a bit Flipped Classroom-like..." and "Rob filmed himself while making a Structured Mind map" brought in practices of transgressive teaching and rearrangements of subject content and methods. Detailed specifications of how these were used, however, were not in the plan, although, as explained by Thomas, they were sequentially conducted in practice. In contrast, the careful scrolling 21 
lengthways and sideways during interaction, followed by utterances like "Then it must appear in the plan!," as by Oliver, were reminders to the team that the construction work not only was about materializing experiences or new ideas but also about detailing what needs to be done when, by whom, and in what order. Thus, the intermediary object at this stage mediated a more systematic curriculum construction, structuring both the process and what was being constructed. This came into view through the specification efforts, which, in turn, requested them to consider their own construction process.

Third, an overall intention with the local curriculum work was to develop a subject curriculum that would also be valid for future teachers and students. In this episode, the work centered on ensuring consistency in order to secure a common ground, tying together a version of the object sufficiently standardized to be put into use in the future. One of the teachers explained in an interview: "To what extent the subject curriculum should be carved in stone, that's an everlasting discussion. What's important, however, is that this plan helps new employees to know what to do, as a guiding framework." In bringing the future into their present work, they created an intermediary object that mediated a space for exploring long-term scenarios and more systematic work, rather than ad hoc teaching and immediate endeavors. Through the interaction with the knowledge object, we also observed that a collective responsibility for the wider school appeared.

In summary, this episode illustrates how curriculum development also involves epistemic responsibilities for establishing coherence and continuity. When working on the multiple potential connections inherent in the knowledge object, more future-oriented work was possible. Furthermore, the episode showed the continuous stabilization effort through instances that provided ever-new platforms or springboards for further construction of the knowledge object.

\section{Summary of findings}

The analysis showed how the teachers had to explore and materially resolve several sets of problems embedded in the larger knowledge object in order to move on in their development of the plan. By constructing a series of intermediary objects, partial aspects and sets of relations were invoked through which the plan evolved. The analysis of the three episodes showed how such aspects concerned relations between the plan as a shared basis for work and the envisioned 
teaching practice, relations between subject matters, and relations between general regulations for the work with pupils and the form such principles may take in specific educational contexts. Three partial aspects identified in these episodes required responsibilities which took the form of re-contextualizing general principles, validating by examining partial aspects, and creating coherence by consolidating elements. Table 4 depicts the epistemic engagement required in these processes and the extended responsibilities it implied. It also depicts the coordination effort this implied in time and space between intermediary objects and the wider curriculum framework.

\section{Table 4}

Intermediary objects and epistemic responsibilities in local curriculum development

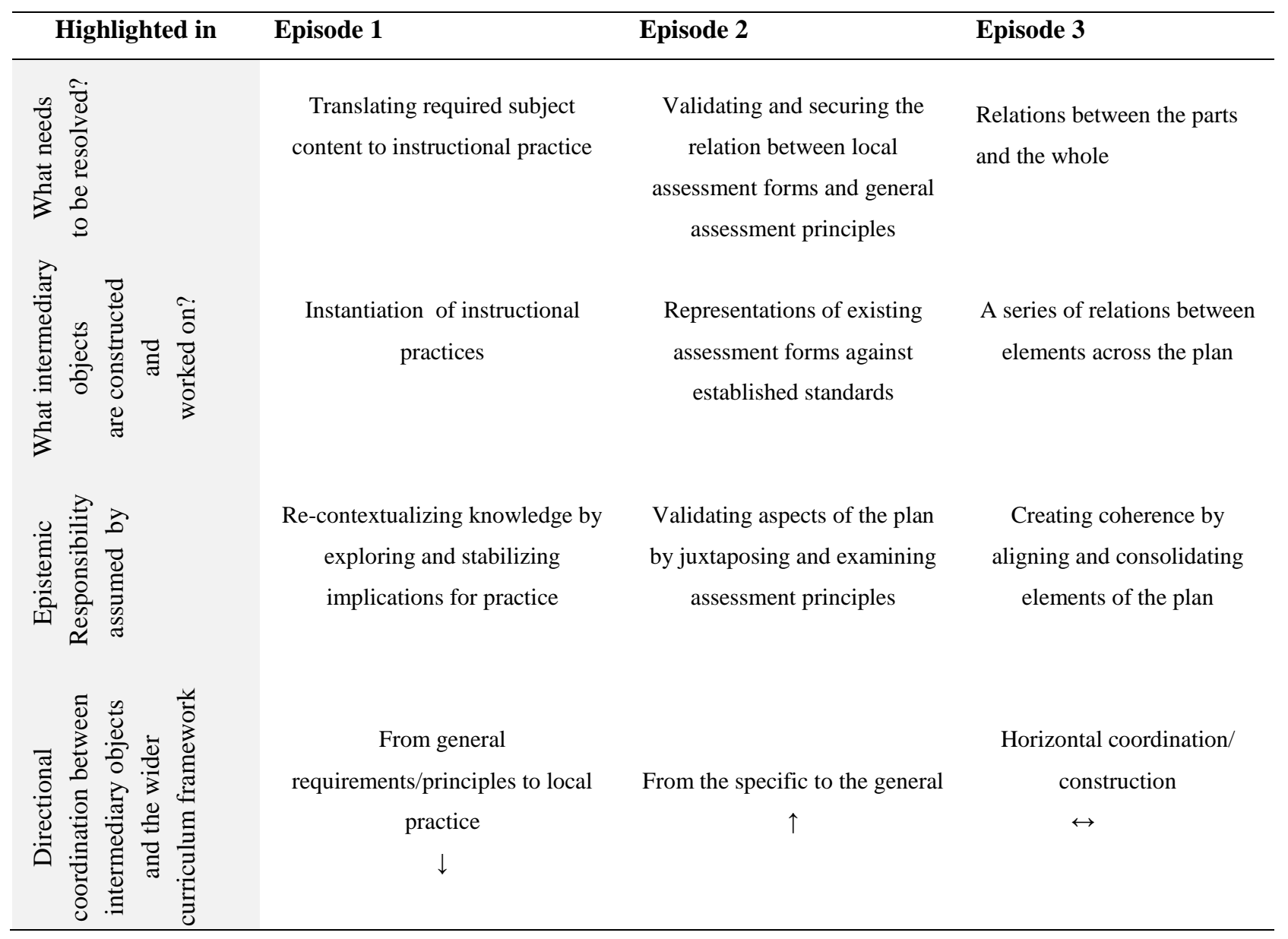


Neither form of object construction was straightforward. Rather, they all required a set of advanced epistemic actions from the teachers in the sense of generating ideas, experimenting with and testing out scenarios, and aligning existing and imagined instructional practices with standards and regulatory frameworks of various kinds. Such actions were needed to materialize the design process in the development of the plan. At the same time, through the construction of intermediate objects, the teachers could frame problems and define avenues for further exploration.

The analysis also revealed how wider sets of relations were invoked in the process, such as relations to the planning work of other teacher teams, relations to the school's wider epistemic and social environment, and relations to the pupils' educational trajectories. The kinds of relations that were worked on, however, were dependent on how the intermediate objects were constituted in the teachers' work. In the first two episodes, relations between the plan-in-themaking and its wider educational context were instantiated as problems to resolve, while the object construction in the last episode takes place within the frames of the plan and its multiple internal components. In the design process we followed as a whole, the teachers moved inbetween such object constellations. The teachers also returned to previously resolved issues and reopened them for further exploration as other parts of the plan progressed. Different relations, temporalities, and requirements were transformed in and through the plan as it developed over time.

\section{Discussion}

This study has shown how curriculum development is a multifaceted process that constantly moves back and forth in time and space, as the teachers work on different aspects and partial problems of the knowledge object. As also noted by Voogt et al. (2011), the process involves the construction, adaptation, and redesign of different curriculum materials. Furthermore, teachers engage with past practices - as in the modeling example above - and with future scenarios in their efforts to juxtapose the various aspects. The findings are in line with previous studies of teachers' collaborative curriculum work that pointed to how such work involves negotiation and the reconstruction of relations to practices in other places and times (Baker-Doyle \& Gustavsen, 2016; Author, 2014; Priestley et al., 2012). At the same time, the present study underscores how 
the design process had a multifaceted, yet sequential, organization in which phases that often are described in terms of development and implementation actually co-evolved through the process in a complex interplay between the teachers and their material objects. The process we observed was iterative, in which the generation, imaginary testing, and validation of ideas were important to drive the process forward. To further understand the mechanisms through which this process evolved, we now turn to the contributions of the objects and the teachers respectively.

First, as suggested by Vinck (2012), intermediate objects work on the construction process in several ways: They delimit a space for action, they mediate a common ground for joint exploration and problem solving, and they shape the temporal dynamics within which explorative and constructive actions may unfold. In the present study, these functions became visible as the teachers' temporary constructions defined relations between specific curricular elements as a problem space, such as the relation between assessment forms and general principles in episode 2 . The oscillation between defining a problem space, exploring different elements and relations within this space, and arriving at temporary solutions manifested in the written plan constitute a key dynamism that drives the curriculum development forward. Through these openings and closings of problems, the plan-in-the making takes the form of an unfolding knowledge object. As pointed out by Knorr Cetina (2001), every knowledge object has multiple instantiations, but these are only accessible as versions or partial realizations of an ideational object. When aspects of the larger object are worked on, this work is mediated by the knowledge object's partial material representations — what we, using Vinck's terminology, called intermediary objects. These objects allow ideas and unfulfilled opportunities to become externalized as something teachers can share, explore, and develop further. We could add that the process does not stop here: As the plan becomes shared in the wider teacher community and used as a basis for the planning and enacting of classroom activities in the years to come, the plan is likely to take on similar functions for new groups of actors, who also would need to explore and construct intermediate objects in their everyday teaching practice. New practices and actors will then be enrolled in the process and contribute to the further life of the subject curriculum as a shared, unfolding knowledge object. 
Second, the way the intermediary objects are brought to life and given temporary form rests on a series of epistemic actions from the teachers' side. By analyzing the planning process as object construction, we identified different types of epistemic engagement that were needed to keep the plan unfolding and to construct intermediate objects. The details of such work have not been explored much in teachers' practice; however, it is striking how the process involves similar types of actions as those found in design processes within other professions. For instance, Comi and Whyte (2017) identified imagining, testing, stabilizing, and reifying as central practices involved in architectural design, in which the use of visual artifacts, such as drawings, models, and texts, plays a key role. In the nursing profession, efforts to develop shared clinical procedures and work descriptions involved exploration of external knowledge sources, juxtaposing of existing and imagined practices, and integration of different knowledge forms, testing, and validation as key steps to arrive at an agreed-upon recommendation (Author, 2012). The present study showed how the teachers also engaged in developing and testing ideas, stabilizing temporary objects, exploring connections between the local and the universal, and securing productive relations between various elements of the plan. In addition, the teachers had to validate their curriculum design by aligning elements with wider curriculum frameworks. This underscores that curriculum development is a complex epistemic activity, which requires teachers to actively engage in exploring, transforming, and safeguarding knowledge resources for professional work. Thus, curriculum development requires new forms of agency from teachers (Priestley et al., 2012) and, we would add, epistemic agency in the form of extended responsibilities taken on by the teachers. By understanding such work through the lenses of object construction, this study has shown how collaborative work around knowledge objects generates critical validations of, elaboration, and further development of professional resources and curriculum-related knowledge.

\section{Conclusions and implications}

Teachers' work and responsibilities are changing as society becomes more complex and the expectations for schooling intensify and expand. Although the social dimension of professional responsibilities is generally acknowledged, less attention has been given to epistemic aspects. This article has shown how local curriculum development presents teachers with a range of epistemic challenges and opportunities, which are handled through active construction and 26 
exploration of curricular elements and the way they are connected within and beyond the school. We have depicted the process as emerging through co-construction of a series of intermediary objects. Moreover, by regarding the curriculum-in-the making as an unfolding knowledge object, we have pointed to the significant role material resources take in the process. Teachers' access to artefacts and tools of various kinds, and the teachers' capacity to make productive use of these tools in the design process, is crucial for their curriculum development. Our case showed how the teachers' work on the subject curriculum was intertwined with a series of other plans and curriculum templates, and thus embedded in local and extended knowledge networks.

What implications might this complexity have for schools and for the preparation of prospective teachers? First, we argue there is a need to recognize the types of epistemic engagement revealed here as important to teachers' professional competencies. In work settings, this means that the planning of teaching should be seen as a creative-constructive activity rather than as a straightforward implementation issue. Therefore, it is important to acknowledge curriculum development as an ongoing design process, and provide teachers with sufficient space and resources to take collective responsibility for developing local plans and activities in relation to wider frameworks. However, as we have seen in our case, collective responsibility requires leadership and extensive coordination of times and tasks across the school to be possible to realize. In turn, this implies shifting attention from the individual teachers' professional autonomy and results to the performances of the collaborative community of teachers in the school. The process we analyzed in this article could not have been accomplished by one teacher alone. Understanding teachers' work through the lenses of design and object construction could be one way forward.

Second, we suggest that teacher education programs should aspire to include curriculum design processes as important learning activities. For instance, they could take the form of collaborative and work-related projects across subject specialties. Or they could be developed in close connection with schools hosting students for practicums or internships in which actors of different sites could participate on shared objects, as discussed in teacher education contexts by Vestøl and Lund (2017). However, then it is important to consider what it takes to engage in such construction processes. The team we followed in this article included mainly experienced 
teachers with high levels of professional expertise. Newcomers to the profession would need to develop an in-depth understanding of pedagogical processes to be able to engage in a similar vein. This relationship between how constructive activities can be organized and supported in educational and professional contexts would be an interesting topic for exploration in further research.

\section{Funding}

This research did not receive any specific grant from funding agencies in the public, commercial, or not-for-profit sectors.

\section{Acknowledgements}

We are grateful to Professor Andreas Lund, University of Oslo, and members of the EXCiD junior research group at the Department of Education, University of Oslo, for constructive feedback on previous versions of this article. We also thank the participating teachers for the research opportunities enabled by their work. Finally, we thank the anonymous reviewers for their valuable comments. 


\section{References}

Baker-Doyle, K. J., \& Gustavson, L. (2016). Permission-seeking as an agentive tool for transgressive teaching: An ethnographic study of teachers organizing for curricular change. Journal of Educational Change, 17(1), 51-84.

Binkhorst, F., Handelzalts, A., Poortman, C. L., \& Van Joolingen, W. R. (2015). Understanding teacher design teams-A mixed methods approach to developing a descriptive framework. Teaching and Teacher Education, 51, 213-224.

Bruni, A. (2005). Shadowing software and clinical records: On the ethnography of non-humans and heterogeneous contexts. Organization, 12(3), 357-378.

Coburn, C. E. (2001). Collective sensemaking about reading: How teachers mediate reading policy in their professional communities. Educational Evaluation and Policy Analysis, 23(2), 145-170.

Comi, A., \& Whyte, J. (2017). Future making and visual artefacts: An ethnographic study of a design project. Organization Studies. Advance online publication. doi:10.1177/0170840617717094

Czarniawska-Joerges, B. (2007). Shadowing and other techniques for doing fieldwork in modern societies. Copenhagen: Copenhagen Business School Press.

Czerniawski, G. (2011). Emerging teachers-emerging identities: Trust and accountability in the construction of newly qualified teachers in Norway, Germany, and England. European Journal of Teacher Education, 34(4), 431-447.

Ewenstein, B., \& Whyte, J. (2009). Knowledge practices in design: The role of visual representations as epistemic objects. Organization Studies, 30(1), 7-30.

Fenwick, T., Edwards, R., \& Sawchuk, P. (2011). Emerging approaches to educational research: Tracing the socio-material. Abingdon: Routledge.

Author (2012). [details removed for peer review].

Fransson, G., \& Grannäs, J. (2013). Dilemmatic spaces in educational contexts - Towards a conceptual framework for dilemmas in teachers work. Teachers and Teaching, 19(1), 4-17.

Goodyear, P. (2015). Teaching as design. HERDSA Review of Higher Education, 2, 27-50.

Handelzalts, A. (2009). Collaborative curriculum development in teacher design teams (Doctoral thesis). University of Twente, Enschede.

Hatch, T. (2013). Beneath the surface of accountability: Answerability, responsibility and capacitybuilding in recent education reforms in Norway. Journal of Educational Change, 14(2), 113-138.

Hermansen, H. (2017). Knowledge relations and epistemic infrastructures as mediators of teachers' collective autonomy. Teaching and Teacher Education, 65, 1-9.

Author, M. (2014). [details removed for peer review]. 
Horn, I. S., \& Little, J. W. (2010). Attending to problems of practice: Routines and resources for professional learning in teachers' workplace interactions. American Educational Research Journal, 47(1), 181-217.

Huizinga, T., Handelzalts, A., Nieveen, N., \& Voogt, J. M. (2014). Teacher involvement in curriculum design: Need for support to enhance teachers' design expertise. Journal of Curriculum Studies, 46(1), 33-57.

Jonasson, C., Mäkitalo, Å., \& Nielsen, K. (2015). Teachers' dilemmatic decision-making: Reconciling coexisting policies of increased student retention and performance. Teachers and Teaching, 21(7), 831-842.

Jordan, B., \& Henderson, A. (1995). Interaction analysis: Foundations and practice. Journal of the Learning Sciences, 4(1), 39-103.

Kirk, D., \& MacDonald, D. (2001). Teacher voice and ownership of curriculum change. Journal of Curriculum Studies, 33(5), 551-567.

Knorr Cetina, K. (1999). Epistemic cultures: How the sciences make knowledge. Cambridge, MA: Harvard University Press.

Knorr Cetina, K. (2001). Objectual practice. In T. R. Schatzki, K. Knorr Cetina, \& E. von Savigny (Eds.), The practice turn in contemporary theory (pp. 175-188). London, England: Routledge.

Law, E. H.-F., \& Nieveen, N. (Eds.). (2010). Schools as curriculum agencies: Asian and European perspectives on school-based curriculum development. Rotterdam: Sense.

Lewis, C. C., Perry, R. R., \& Hurd, J. (2009). Improving mathematics instruction through lesson study: A theoretical model and North American case, or effects on curriculum change. Journal of Mathematics Teacher Education, 12(4), 285-304.

McGivern, G., \& Dopson, S. (2010). Inter-epistemic power and transforming knowledge objects in a biomedical network. Organization Studies, 31(12), 1667-1686.

McKenney, S., Kali, Y., Markauskaite, L., \& Voogt, J. (2015). Teacher design knowledge for technology enhanced learning: An ecological framework for investigating assets and needs. Instructional Science, 43(2), 181-202.

McKenney, S., Nieveen, N., \& van den Akker, J. (2006). Design research from a curriculum perspective.

In J. van den Akker, K. Gravemeijer, S. McKenney, \& N. Nieveen (Eds.), Educational design research

(pp. 67-90). London: Routledge.

Miettinen, R., \& Paavola, S. (2016). Reconceptualizing object construction: The dynamics of building information modelling in construction design. Information Systems Journal. doi:10.1111/isj.12125

Author (2012). [details removed for peer review].

Pepin, B., Xu, B., Trouche, L., \& Wang, C. (2017). Developing a deeper understanding of mathematics teaching expertise: An examination of three Chinese mathematics teachers' resource systems as windows into their work and expertise. Educational Studies in Mathematics, 94(3), 257-274.

Plomp, T. (2013). Educational design research: An introduction. In T. Plomp \& Nieveeen (Eds.), Educational design research - Part A: An introduction (pp.10-51). Enschede, the Netherlands: SLO. 
Priestley, M., \& Drew, V. (2017). Teacher sense-making in school-based curriculum development through critical collaborative professional enquiry. In M. A. Peters, B. Cowie, \& I. Menter (Eds.), A companion to research in teacher education (pp. 769-783). Singapore: Springer Singapore.

Priestley, M., Edwards, R., Priestley, A., \& Miller, K. (2012). Teacher agency in curriculum making: Agents of change and spaces for manoeuvre. Curriculum Inquiry, 42(2), 191-214.

Pyhältö, K., Pietarinen, J., \& Soini, T. (2015). Teachers' professional agency and learning - From adaption to active modification in the teacher community. Teachers and Teaching, 21(7), 811830.

Shawer, S. F. (2010). Classroom-level curriculum development: EFL teachers as curriculum-developers, curriculum-makers and curriculum-transmitters. Teaching and Teacher Education, 26(2), 173184.

Van den Akker, J., Gravemeijer, K, McKenney, S., \& Nieveen, N. (Eds.). (2006). Educational design research. London: Routledge.

Van den Akker, J., \& Kuiper, W (2008). Research on models for instructional design: Towards more productive approaches. In J. Spector, D. Merril, J. van Merrienboer, \& M. Driscoll (Eds.), Handbook of research on educational technology and communications (3rd ed., pp. 739-748). Mahwah, NJ: Lawrence Erlbaum Associates.

Vescio, V., Ross, D., \& Adams, A. (2008). A review of research on the impact of professional learning communities on teaching practice and student learning. Teaching and Teacher Education, 24(1), 80-91.

Vestøl, J. M., \& Lund, A. (2017). Co-configuring design elements and quality aspects in teacher education: A research agenda. In M. A. Peters, B. Cowie, \& I. Menter (Eds.), A companion to research in teacher education (pp. 725-739). Singapore: Springer Singapore.

Vinck, D. (2012). Accessing material culture by following intermediary objects. In L. Naidoo (Ed.), An ethnography of global landscapes and corridors (pp. 89-108). London: InTech [Digital Editions Version]. doi:10.5772/34719

Vinck, D., Jeantet, A., \& Laureillard, P. (1996). Objects and other intermediaries in the sociotechnical process of product design: An exploratory approach. In J. Perrin \& D. Vinck (Eds.), The role of design in the shaping of technology (pp. 297-320). European Commission Directorate-General Science. Research and Development: Brussels.

Voogt, J., Westbroek, H., Handelzalts, A., Walraven, A., McKenney, S., Pieters, J., \& De Vries, B. (2011). Teacher learning in collaborative curriculum design. Teaching and Teacher Education, 27(8), 1235-1244.

Voogt, J., Laferrière, T., Breuleux, A., Itow, R. C., Hickey, D. T., \& McKenney, S. (2015). Collaborative design as a form of professional development. Instructional Science, 43(2), 259-282. 